\title{
Sebaran Horizontal Konsentrasi Nitrat Dan Fosfat Anorganik Di Perairan Muara Sungai Kendal, Kabupaten Kendal
}

\section{Horizontal Distribution Of Inorganic Nitrate And Phosphate Concentrations In The Water Of Kendal River Estuary, Kendal District}

\author{
Dwi Nur Hanifah¹, Sri Yulina Wulandari ${ }^{1 *}$, Lilik Maslukah', dan \\ Endang Supriyantini ${ }^{2}$
}

\author{
${ }^{1}$ Departemen Oseanografi, Fakultas Perikanan dan IImu Kelautan, Universitas Diponegoro \\ ${ }^{2}$ Departeman Kelautan, Fakultas Perikanan dan Ilmu Kelautan, Universitas Diponegoro \\ Jl. Prof. H. Soedarto, S. H, Tembalang, Semarang, Jawa Tengah 50275 Indonesia \\ *Email: yulina.wuland@gmail.com
}

\begin{abstract}
ABSTRAK
Muara sungai Kendal banyak dimanfaatkan untuk berbagai aktivitas masyarakat seperti pemukiman penduduk, industri, pertambakan dan Tempat Pelelangan Ikan. Aktivitas masyarat di sekitar sungai Kendal akan mempengaruhi kondisi perairan di muara sungai Kendal. Penelitian ini dilaksanakan pada bulan November 2017. Tujuan penelitian ini adalah untuk mengetahui sebaran konsentrasi nitrat dan fosfat anorganik secara horizontal di permukaan perairan muara sungai Kendal. Pengambilan sampel dilakukan pada 12 stasiun menggunakan metode purposive sampling dengan pertimbangan dapat mewakili wilayah muara sungai, dekat pantai, wilayah transisi dan laut. Data utama meliputi konsentrasi nitrat dan fosfat. Data pendukung meliputi suhu, salinitas, DO, $\mathrm{pH}$ dan kecerahan yang diukur secara langsung di lapangan, serta data yang diperoleh dari berbagai instansi terkait. Hasil penelitian menunjukkan bahwa konsentrasi nitrat dan fosfat semakin menurun menuju laut. Konsentrasi nitrat

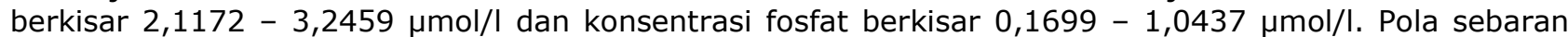
konsentrasi nitrat dan fosfat tidak mengikuti pola arus.
\end{abstract}

Kata kunci : nitrat, fosfat, sebaran, muara Sungai Kendal

\begin{abstract}
The estuary of Kendal is widely used for various activities such as residential, industrial, fishpond and fish auction places. Activity around the Kendal river will affect the conditions at the estuary of Kendal. This research was conducted in November 2017. The purpose of this research was to know the distribution of nitrate and inorganic phosphate concentration horizontally at surface of estuary Kendal. Sampling was conducted on 12 stations used purposive sampling method with consideration to represent the estuary, near shore, transition area and the sea. The Primary data included nitrate and phosphate concentrations. Supporting data included temperature, salinity, DO, $\mathrm{pH}$ and brightness measured directly in the field, as well as data obtained from various related agencies. The results showed that the concentration of nitrate and phosphate decreased toward the sea. Nitrate concentrations ranged from $2.1172-3.2459 \mu \mathrm{mol} / \mathrm{l}$ and phosphate concentrations ranged from $0.1699-1.0437 \mu \mathrm{mol} / \mathrm{l}$. The distribution pattern of nitrate and phospate concentration did not follow the current pattern.
\end{abstract}

Keywords : nitrate, phosphate, distribution, Estuary of Kendal

\section{PENDAHULUAN}

Muara sungai merupakan bagian ekosistem di wilayah pesisir berupa pantai semi tertutup (semi-enclosed) yang mempunyai hubungan langsung dengan laut (Zulhaniarta et al., 2015). Swayati et al. (2015) menyatakan, bahwa di wilayah muara sungai selalu terjadi perubahan lingkungan baik secara fisika, kimia maupun biologi. Proses perubahan lingkungan ini akan mempengaruhi persebaran zat hara di wilayah pesisir dan muara (Hidayah et al., 2016). Kandungan zat hara di daerah muara sungai adalah tinggi, dikarenakan di Kawasan ini terjadi pengendapan bahan organik akibat masukan dari daratan. Zat hara fosfat dan nitrat sangat diperlukan fitoplankton untuk 
kelangsungan hidupnya. Kedua zat tersebut berperan dalam pembentukan sel jaringan jasad hidup organisme dan proses fotosintesis (Agustin et al., 2016).

Fosfat dan nitrat digunakan sebagai indikator untuk mengevaluasi kualitas dan tingkat kesuburan perairan. Kandungan nitrat dan fosfat yang terlalu tinggi akan berpengaruh terhadap kualitas perairan, yaitu menyebabkan eutrofikasi. Eutrofikasi perairan akan memicu pertumbuhan fitoplankton yang tidak terkendali. Dampak eutrofikasi di lingkungan perairan adalah berkurangnya oksigen terlarut yang mengakibatkan kematian organisme akuatik lainnya dan keracunan karena zat toksin yang diproduksi oleh fitoplankton (Megawati et al., 2014).

Secara geografis, kabupaten Kendal terletak pada posisi antara $109^{\circ} 40^{\prime}-110^{\circ} 18^{\prime}$ Bujur Timur dan 6०32' - 7024' Lintang Selatan, dengan luas wilayah $1315,43 \mathrm{Km}^{2}$ dan memiliki garis pantai $41,0 \mathrm{~km}^{2}$ (Ismail et al., 2013). Muara sungai Kendal banyak dimanfaatkan warga sekitar untuk pemukiman, industri, tambak, wisata, dan Tempat Pelelangan Ikan Bandengan. Aktivitas masyarakat disekitar sungai Kendal akan mempengaruhi persebaran konsentrasi nitrat dan fosfat di perairan muara sungai Kendal. Tujuan dilakukannya penelitian ini adalah untuk mengetahui sebaran konsentrasi nitrat dan fosfat anorganik secara horizontal di permukaan perairan muara sungai Kendal.

\section{METODE PENELITIAN}

Materi penelitian berupa data sampel air yang diambil dari perairan muara sungai Kendal, Kabupaten Kendal yang selanjutnya dibawa ke laboratorium untuk dianalisis. Pengambilan sampel dilakukan pada bulan November 2017. Data utama dalam penelitian ini berupa data konsentrasi nitrat dan fosfat di perairan muara sungai Kendal, Kabupaten Kendal. Adapun data pendukung meliputi data suhu, salinitas, $\mathrm{pH}, \mathrm{DO}$, kecerahan, arus, Peta Rupa Bumi Indonesia skala 1:25.000 dari Badan Informasi Geospasial dan Peta Bathimetri Perairan Wilayah Jawa Tengah skala 1:200.000.

Metode yang digunakan dalam penelitian ini adalah metode penelitian kuantitatif. Metode kuantitatif merupakan metode penelitian menggunakan data berupa angka-angka dan bersifat sistematis dan menggunakan analisis statistik dengan tujuan untuk menguji hipotesis yang telah ditetapkan (Sugiyono, 2011).

Penentuan lokasi penelitian dilakukan berdasarkan metode purposive sampling dengan mengggunakan GPS (Global Positioning System). Metode purposive sampling yaitu teknik penentuan lokasi pengambilan sampel dengan pertimbangan tertentu sesuai tujuan dan sasaran penelitian (Sugiyono, 2011). Pengambilan sampel dilakukan pada 12 stasiun pengamatan dengan pertimbangan dapat mewakili daerah penelitian secara keseluruhan, yaitu stasiun 1 dan 2 mewakili badan sungai, stasiun 3, 4, 5, dan 6 mewakili daerah muara sungai, stasiun 7,8 , dan 9 mewakili daerah pantai, dan terakhir pada stasiun 10, 11, 12 mewakili daerah laut. Peta lokasi pengambilan sampel air laut dapat dilihat pada Gambar 1 .

Sampel air laut diambil pada saat surut menuju pasang pada lapisan permukaan perairan di setiap stasiun.

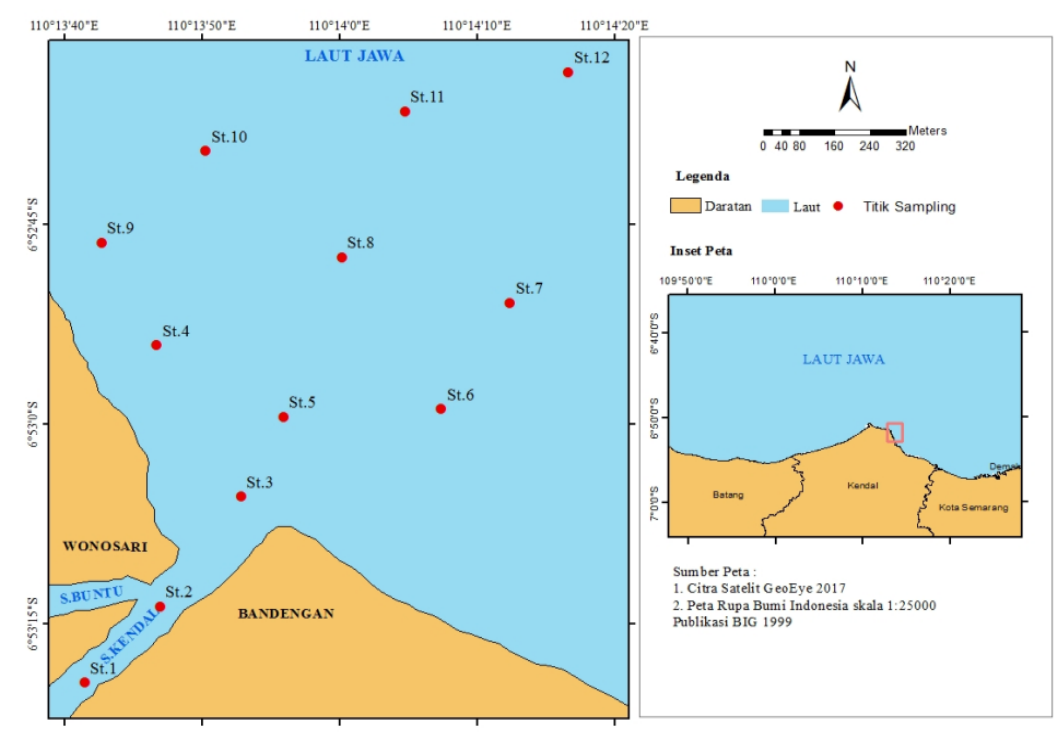

Gambar 1. Peta lokasi pengambilan sampel 
Sampel air dimasukkan ke dalam botol sampel polietilen berukuran $500 \mathrm{ml}$ dan disimpan ke dalam pendingin ( $\mathrm{cool}$ box) untuk menghentikan aktivitas biologi. Data kualitas air seperti suhu, salinitas, $\mathrm{pH}$, dan oksigen terlarut diukur dengan menggunakan water quality checker. Pengambilan data kecerahan dilakukan dengan menggunakan secchi disc. Sementara penentuan konsentrasi nitrat dan fosfat dalam contoh air laut ditentukan dengan mengunakan metode spektrofotometri pada panjang gelombang $880 \mathrm{~nm}$ untuk fosfat dan $540 \mathrm{~nm}$ untuk nitrat (Grasshoff et al., 1999). Hasil analisis nitrat dan fosfat disajikan dalam bentuk peta sebaran menggunakan software arcgis 10.2.

Pengukuran arus dilakukan dengan metode lagrange, yaitu mengamati gerakan massa air permukaan dari satu titik ke titik berikutnya dalam rentang waktu tertentu (Sudarto et al., 2013). Arus tersebut selanjutnya dimodelkan menggunakan software pemodelan hidrodinamika, dan dilakukan verifikasi data model yang bertujuan untuk membandingkan data hasil model dengan data hasil lapangan untuk melihat kesesuaiannya. Verifikasi menggunakan persamaan Cost Function (CF). Kriteria kelayakan nilai model jika $C F<1$ adalah sangat baik, 1-2 adalah baik, 2-3 adalah wajar, $>3$ adalah buruk. Perhitungan berdasarkan George et al. (2010).

\section{HASIL DAN PEMBAHASAN}

Hasil penelitian konsentrasi nitrat di perairan muara sungai Kendal berkisar 2,1172-3,2459 $\mu \mathrm{mol} / \mathrm{l}$. Konsentrasi nitrat tertinggi terdapat pada stasiun 3 yaitu sebesar 3,2459 $\mu \mathrm{mol} / \mathrm{l}$ dan konsentrasi terendah terdapat pada stasiun 12 yaitu sebesar 2,1172 $\mu \mathrm{mol} / \mathrm{l}$. Rata-rata nilai konsentrasi nitrat sebesar 2,7928 $\mu \mathrm{mol} / \mathrm{l}$.

Konsentrasi fosfat anorganik di perairan muara sungai Kendal berkisar 0,1699-1,0437 $\mu \mathrm{mol} / \mathrm{l}$. Konsentrasi fosfat tertinggi terdapat pada stasiun 1 sebesar $1,0437 \mu \mathrm{mol} / \mathrm{I}$ dan konsentrasi terendah terdapat pada stasiun 12 sebesar 0,1699 $\mu \mathrm{mol} / \mathrm{l}$. Rata-rata nilai konsentrasi fosfat adalah 0,6294 $\mu \mathrm{mol} / \mathrm{l}$. Hasil analisis konsentrasi nitrat dan fosfat dapat dilihat pada Tabel 1 sedangkan untuk sebaran konsentrasi nitrat dan fosfat dapat dilihat pada Gambar 2 dan 3.

Hasil pengukuran arus laut di perairan muara sungai Kendal menunjukkan bahwa arah arus permukaan dominan ke arah Tenggara. Kecepatan arus permukaan maksimum terletak di stasiun 3 yang mencapai $0,0617 \mathrm{~m} / \mathrm{s}$, sedangkan kecepatan arus permukaan minimum terdapat di stasiun 1 dengan kecepatan 0,0256 m/s. Hasil pengukuran arus permukaan secara lengkap disajikan pada Tabel 2.

Pola arus hasil pemodelan di perairan muara Sungai Kendal diverifikasi dengan data arus lapangan. Hasil pemodelan arus di perairan muara Sungai Kendal (Gambar 4).

Berdasarkan hasil yang diperoleh, konsentrasi nitrat tertinggi yaitu sebesar 3,2459 $\mu \mathrm{mol} / \mathrm{l}$ terdapat pada stasiun $3 \mathrm{di}$ muara sungai Kendal. Tingginya konsentrasi nitrat pada stasiun 3 diduga akibat adanya resuspensi sedimen, hal ini dibuktikan dengan tingginya arus pada stasiun 3 yaitu sebesar 0,0617 m/s (Tabel 7). Rigitta et al. (2015) menyatakan, arus yang tinggi dapat mengakibatkan terjadinya resuspensi sedimen. Proses resuspensi dapat menyebabkan sedimen yang berada di dasar laut naik ke kolom air sehingga nitrat yang berada di dasar laut juga ikut terangkat ke kolom air. Hal ini diperkuat oleh pernyataan Dzialowski et al. (2008), bahwa resuspensi sedimen merupakan salah satu proses yang berpotensi memberikan kontribusi masukan nutrien penting seperti nitrat ke kolom air.

Konsentrasi nitrat terendah yaitu sebesar $2,1172 \mu \mathrm{mol} / \mathrm{l}$ berada pada stasiun 12 . Hal ini disebabkan stasiun 12 terletak jauh dari muara sungai. Fakta tersebut sesuai dengan pendapat Rigitta et al. (2015), bahwa semakin jauh dari pengaruh daratan maka suplai nitrat menurun sehingga mengakibatkan konsentrasi nitrat yang rendah. Rendahnya konsentrasi nitrat pada stasiun 12 ini ditandai dengan nilai salinitas yang tinggi yaitu sebesar $34,6 \%$. Utami et al. (2016) menyatakan, bahwa konsentrasi nitrat akan menurun seiring dengan meningkatnya salinitas. Berdasarkan hasil yang diperoleh, dapat dilihat bahwa sebaran konsentrasi nitrat secara horizontal mengalami penurunan semakin menuju laut. $\mathrm{Hal}$ ini diperkuat oleh pernyataan Karil et al. (2014), bahwa konsentrasi nitrat tertinggi berada pada wilayah muara sungai dan semakin menurun menuju laut.

Konsentrasi fosfat tertinggi yaitu sebesar $1,0437 \mu \mathrm{mol} / \mathrm{l}$ terdapat pada stasiun 1 di badan sungai Kendal. Tingginya konsentrasi fosfat pada stasiun 1 diduga karena letak stasiun 1 berada dekat pemukiman penduduk, dalam hal ini limbah dari berbagai aktivitas penduduk seperti pemukiman, pertambakan, aktivitas nelayan 
Tabel 1. Hasil analisis konsentrasi nitrat dan fosfat

\begin{tabular}{cccc}
\hline No. & Nama Stasiun & $\begin{array}{c}\text { Konsentrasi Nitrat } \\
(\mu \mathrm{mol} / \mathrm{I})\end{array}$ & $\begin{array}{c}\text { Konsentrasi fosfat } \\
\text { anorganik }(\mu \mathrm{mol} / \mathrm{I})\end{array}$ \\
\hline 1 & Stasiun 1 & 3,0473 & 1,0437 \\
2 & Stasiun 2 & 3,0524 & 0,9417 \\
3 & Stasiun 3 & 3,2450 & 0,9078 \\
4 & Stasiun 4 & 2,9343 & 0,7767 \\
5 & Stasiun 5 & 3,0985 & 0,8786 \\
6 & Stasiun 6 & 2,9225 & 0,7379 \\
7 & Stasiun 7 & 2,8701 & 0,5243 \\
8 & Stasiun 8 & 2,7821 & 0,4709 \\
9 & Stasiun 9 & 2,6218 & 0,4612 \\
10 & Stasiun 10 & 2,6112 & 0,3883 \\
11 & Stasiun 11 & 2,2110 & 0,2524 \\
12 & Stasiun 12 & 2,1172 & 0,1699 \\
\hline
\end{tabular}

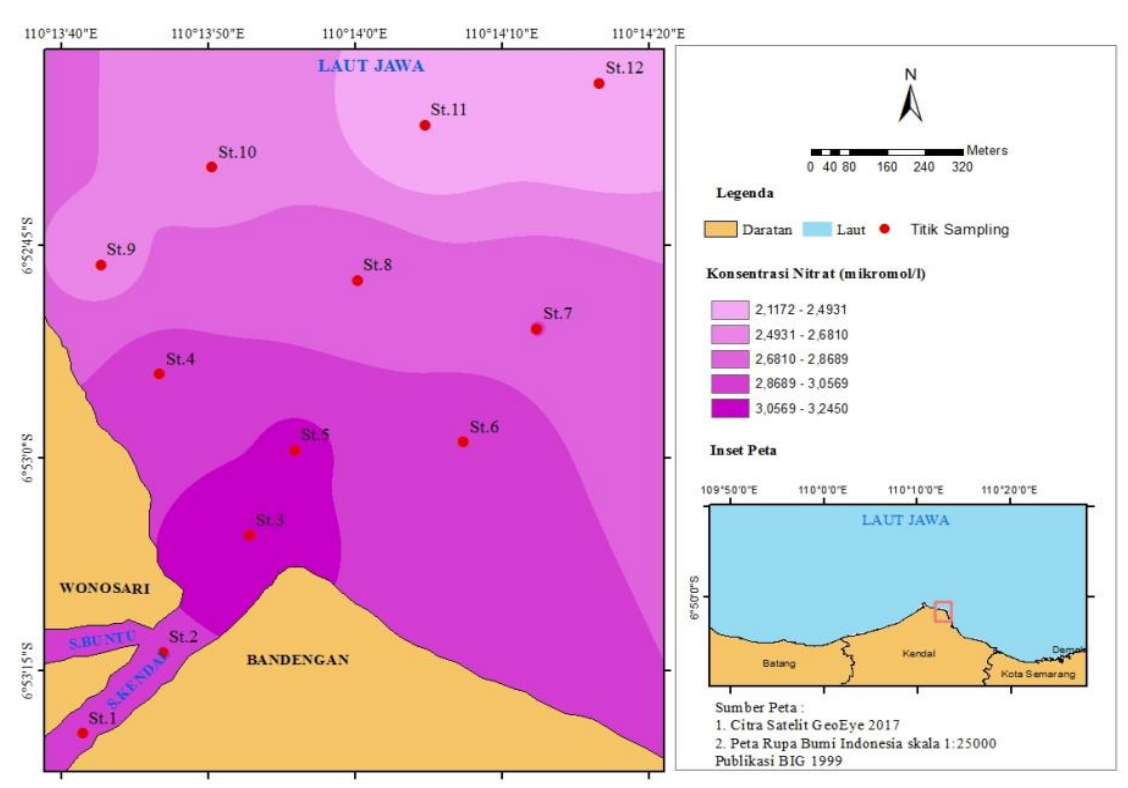

Gambar 2. Sebaran konsentrasi nitrat $(\mu \mathrm{mol} / \mathrm{l})$ di Perairan Muara Sungai Kendal

dan kegiatan pengolahan ikan di kawasan Bandengan dibuang langsung ke sungai sehingga menyebabkan kandungan fosfat tinggi. Aktivitas masyarakat yang membuang limbah langsung ke sungai, terutama limbah rumah tangga yang mengandung detergen juga dapat meningkatkan konsentrasi fosfat di perairan. Hal ini diperkuat oleh pernyataan Tungka et al. (2016), bahwa limbah rumah tangga berupa deterjen dapat meningkatkan konsentrasi fosfat di perairan, karena salah satu komposisi penyusun detergen adalah ion fosfat. Ulqodry et al. (2010) menyatakan, bahwa sungai merupakan salah satu media pembawa hanyutan limbah maupun sumber fosfat dari daratan, sehingga akan mengakibatkan konsentrasi fosfat lebih tinggi dari pada daerah sekitarnya.
Konsentrasi fosfat terendah sebesar $0,1699 \mu \mathrm{mol} / \mathrm{l}$ terdapat pada stasiun 12 . Rendahnya konsentrasi fosfat pada stasiun 12 disebabkan lokasi berada jauh dari muara sungai Kendal sebagai sumber fosfat ke perairan laut. Fakta tersebut sesuai dengan pendapat Megawati et al. (2014), bahwa kandungan fosfat pada umumnya akan semakin berkurang apabila semakin jauh menuju ke arah laut. Rendahnya kandungan fosfat pada stasiun 12 ini ditandai dengan tingginya kecerahan pada stasiun 12 yaitu $200 \mathrm{~cm}$, dalam hal ini pada stasiun tersebut sudah sangat minim terjadinya proses resuspensi sedimen. Kecerahan yang tinggi menandakan bahwa perairan memiliki bahan organik yang sedikit sehingga konsentrasi fosfat rendah. 


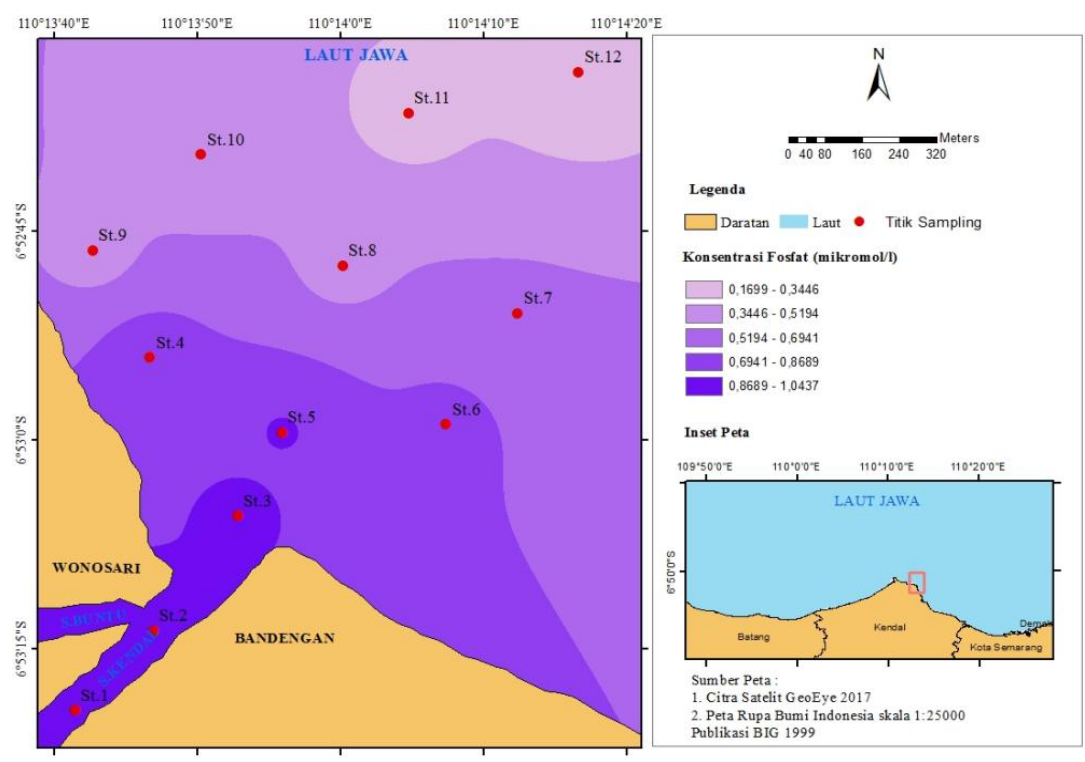

Gambar 3. Sebaran konsentrasi fosfat anorganik $(\mu \mathrm{mol} / \mathrm{l})$ di Perairan Muara Sungai Kendal

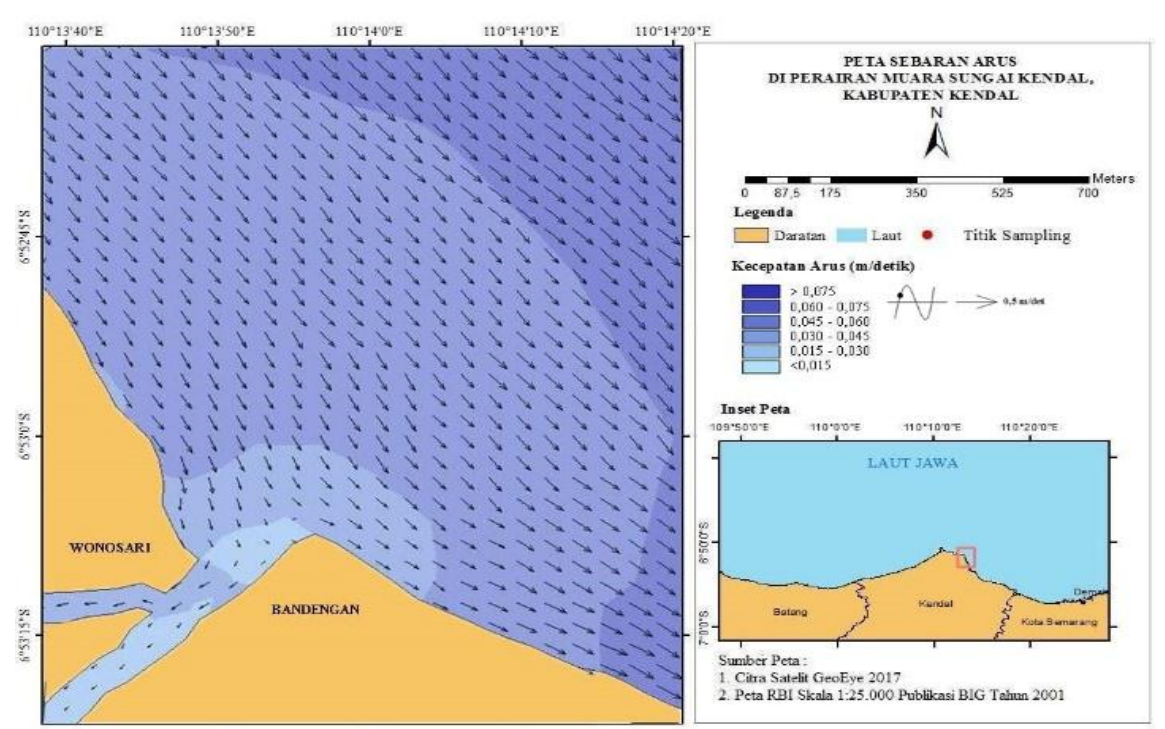

Gambar 4. Hasil Pemodelan Arus Di Perairan Muara Sungai Kendal, Kabupaten Kendal

Tabel 2. Kecepatan dan Arah Arus Permukaan Perairan Muara sungai Kendal

\begin{tabular}{cccccc}
\hline Stasiun & Lintang & Bujur & Kecepatan (m/det) & Posisi (derajat) & Arah \\
\hline 1 & $6^{\circ} 53^{\prime} 16,92^{\prime \prime} \mathrm{S}$ & $110^{\circ} 13^{\prime} 44,09^{\prime \prime} \mathrm{E}$ & 0,0256 & $141^{0}$ & Tenggara \\
2 & $6^{\circ} 53^{\prime} 13.34^{\prime \prime} \mathrm{S}$ & $110^{\circ} 13^{\prime} 47,68^{\prime \prime} \mathrm{E}$ & 0,0347 & $128^{0}$ & Tenggara \\
3 & $6^{\circ} 53^{\prime} 09.11^{\prime \prime} \mathrm{S}$ & $110^{\circ} 13^{\prime} 50,94^{\prime \prime} \mathrm{E}$ & 0,0617 & $98^{0}$ & Timur \\
4 & $6^{\circ} 52^{\prime} 58.04^{\prime \prime} \mathrm{S}$ & $110^{\circ} 13^{\prime} 47,70^{\prime \prime} \mathrm{E}$ & 0,0523 & $110^{0}$ & Timur \\
5 & $6^{\circ} 53^{\prime} 01.95^{\prime \prime} \mathrm{S}$ & $110^{\circ} 13^{\prime} 54,86^{\prime \prime} \mathrm{E}$ & 0,0320 & $193^{0}$ & Selatan \\
6 & $6^{\circ} 53^{\prime} 05.87^{\prime \prime} \mathrm{S}$ & $110^{\circ} 13^{\prime} 57,79^{\prime \prime} \mathrm{E}$ & 0,0259 & $176^{0}$ & Selatan \\
7 & $6^{\circ} 52^{\prime} 58.06^{\prime \prime} \mathrm{S}$ & $110^{\circ} 14^{\prime} 01.71^{\prime \prime} \mathrm{E}$ & 0,0260 & $150^{\circ}$ & Tenggara \\
8 & $6^{\circ} 52^{\prime} 55.12^{\prime \prime} \mathrm{S}$ & $110^{\circ} 13^{\prime} 54.87^{\prime \prime} \mathrm{E}$ & 0,0346 & $145^{0}$ & Tenggara \\
9 & $6^{\circ} 52^{\prime} 50.87^{\prime \prime} \mathrm{S}$ & $110^{\circ} 13^{\prime} 43.80^{\prime \prime} \mathrm{E}$ & 0,0262 & $140^{\circ}$ & Tenggara \\
10 & $6^{\circ} 52^{\prime} 47.95^{\prime \prime} \mathrm{S}$ & $110^{\circ} 13^{\prime} 50.98^{\prime \prime} \mathrm{E}$ & 0,0343 & $150^{\circ}$ & Tenggara \\
11 & $6^{\circ} 52^{\prime} 47.96^{\prime \prime} \mathrm{S}$ & $110^{\circ} 13^{\prime} 57.82^{\prime \prime} \mathrm{E}$ & 0,0401 & $110^{0}$ & Tenggara \\
12 & $6^{\circ} 52^{\prime} 47.97^{\prime \prime} \mathrm{S}$ & $110^{\circ} 14^{\prime} 05.96^{\prime \prime} \mathrm{E}$ & 0,0545 & $210^{0}$ & Barat Daya \\
\hline \hline
\end{tabular}


Berdasarkan hasil yang diperoleh, dapat dilihat bahwa sebaran konsentrasi nitrat dan fosfat secara horizontal mengalami penurunan semakin menuju laut. Sebaran konsentrasi nitrat dan fosfat di muara Sungai Kendal tidak mengikuti pola arus yang terjadi. Berdasarkan gambar 4, dapat dilihat bahwa pola arus yang terjadi menunjukkan arus bergerak ke arah tenggara. Sebaran konsentrasi nitrat dan fosfat di muara sungai Kendal diduga akibat proses pengenceran dari sumbernya yang berada di daerah muara sungai, sehingga konsentrasinya semakin rendah menuju laut lepas.

\section{KESIMPULAN}

Penelitian yang dilakukan pada bulan November 2017 menunjukkan sebaran konsentrasi nitrat berkisar 2,1172 $\mu \mathrm{mol} / \mathrm{l}$ 3,2459 $\mu \mathrm{mol} / \mathrm{l}$ dan konsentrasi fosfat berkisar 0,1699 $\mathrm{\mu mol} / \mathrm{l}$ - 1,0437 $\mu \mathrm{mol} / \mathrm{l}$. Pola persebaran konsentrasi nitrat dan fosfat secara horizontal mengalami penurunan semakin menuju ke laut. Sebaran konsentrasi nitrat dan fosfat tidak mengikuti pola arus yang terjadi, dalam hal ini persebaran diduga akibat proses pengenceran dari sumbernya yang berada di daerah muara sungai.

\section{REFERENSI}

Agustin, W.A., Romadhon, A. \& Siawanto, A.D. 2016. Studi dan Hubungan Arus Terhadap Sebaran dan Fluktuasi Nutrien (N Dan P) di Perairan Kalianget Kabupaten Sumenep. Seminar Nasional Kelautan, 3(1):120-126.

Dzialowski, A.R., Shih-Hsien, W., NiangChoo, L., Beury, J.H. \& Huggins, D.G. 2008. Effects of Sediment Resuspensions on Nutrient Consentration and Algal Biomass in Reservoirs of The Central Plains. Lake an Reservoir Management, 24:313320.

George, Bertino, Johannessen \& Samulsen. 2010. Validation of a Hybrid Coordinate Ocean Model for the Indian Ocean. J. Operational Oceanograp, 3(2):25-38.

Grasshoff, K., Ehrhardt, M., Kremling, K. \& Anderson, L.G. 1999. Methods of Sea water Analysis. Wiley-VCH. New York.

Hidayah, G., Wulandari, S.Y. \& Zainuri, M. 2015. Studi Sebaran Konsentrasi Klorofil -a Secara Horizontal di Perairan Muara Sungai Silugonggo Kecamatan Batangan, Pati. Bul. Oseano. Mar. 5(1): 52-59.
Ismail, Indriadi, Wijayanto. D., Yulianto. T. \& Suroto. 2013. Analisis Kelayakan Usaha Perikanan Laut Kabupaten Kendal. J. Saintek Perikanan, 8(2):52- 56.

Karil, A. R. F., Yusuf M. \& Maslukah L. 2015. Studi Sebaran Konsentrasi Nitrat dan Fosfat di Perairan Teluk Ujung Batu Jepara. J. Oseano. 4(2):306-392.

Megawati, C., Yusuf M. \& Maslukah L. 2014. Sebaran Kualitas Perairan Ditinjau dari Zat Hara,Oksigen Terlarut dan pH di Perairan Muara Selat Bali Bagian Selatan. J. Oseano. 3(2):142-150.

Rigitta, T. M. A, Maslukah L. \& Yusuf M. 2015. Sebaran Fosfat dan Nitrat di Perairan Morodemak, Kabupaten Demak. J. Oseano., 4(2):415-422.

Sudarto, Patty W. \& Adrie A. 2013. Kondisi Arus Permukaan di Perairan Pantai : Pengamatan dengan metode Lagrangian. J. Ilmu Teknol. Tangkap, 1(3): $98-102$.

Sugiyono. 2011. Metode Kuantitatif, Kualitatif dan R \& D. Ed. 8. Alfabeta, Bandung.

Swayati, D.P., Muskananfola, M.R. \& Rudiyanti, S. 2015. Konsentrasi Klorofil - a, Nitrat dan Fosfat Untuk Menilai Kesuburan Muara Sungai Wakak, Kendal. Diponegoro J. Maquares. 4(4): 71-79.

Tungka, A.W., Haeruddin \& Ain, C. 2016. Konsentrasi Nitrat dan Ortofosfat di Muara Sungai Banjir Kanal Barat Dan Kaitannya dengan Kelimpahan Fitoplankton Harmful Alga Blooms (Habs). Saintek Perikanan. 12(1):4046.

Ulqodry, T.Z., Yulisman, Syahdan, M. \& Santoso. 2010. Karakteristik dan Sebaran Nitrat, Fosfat dan Oksigen Terlarut di Perairan Karimunjawa Tengah. J. Penelitian Sains. 3(1):36-41.

Utami, T.M.R., Maslukah L. \& Yusuf M. 2016. Sebaran Nitrat $\left(\mathrm{NO}_{3}\right)$ dan Fosfat $\left(\mathrm{PO}_{4}\right)$ di Perairan Karangsang Kabupaten Indramayu. J. Bull. Oseano. 13(1):3137.

Zulhaniarta, D., Fauziyah, Sunaryo A.I. \& Aryawati R. 2015. Sebaran Konsentrasi Klorofil -A Terhadap Nutrien di Muara Sungai Banyuasin Kabupaten Banyuasin Provinsi Sumatera Selatan. Maspari J. 7(1):9-20. 